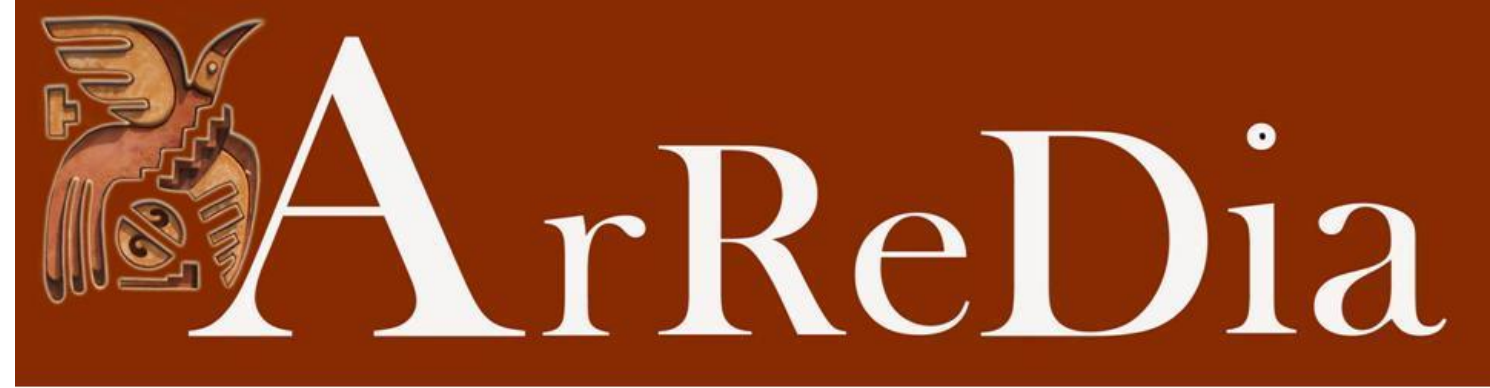

Revista da Faculdade de Comunicação, Artes e Letras / UFGD

\title{
A MULHER NAS PROPAGANDAS DE CERVEJA: UMA ANÁLISE REFERENCIAL
}

\section{Mujeres en los anuncios de cerveza: análisis referencial}

\author{
Cleodete Mendes da Silva ${ }^{i}$ \\ Universidade Federal de Mato Grosso \\ Cristina Batista Araújo ${ }^{i i}$ \\ Universidade Federal do Mato Grosso
}

\begin{abstract}
Resumo: É comum encontrar, nas propagandas de cerveja da propaganda brasileira, a recorrência do discurso midiático com implicações apelativas e com a exploração da sensualidade feminina. Dialogando com esta temática, a presente pesquisa tem como objetivo apontar, em alguns anúncios de cerveja, o discurso usado não apenas para seduzir o consumidor, mas também para estereotipar a mulher, destacando suas características físicas e as igualando a um produto de consumo. Este estudo teve como base teórica de discussão autores como Koch (2004), Marcuschi (2007), com vistas a compreender como os discursos publicitários de propagandas de cerveja estão inscritos na rede discursiva. Procuramos, no decorrer do estudo, investigar como os elementos referenciais da linguagem são articulados para construírem o estereótipo da mulher como objeto de consumo.
\end{abstract}

Palavras-chave: Análise do Discurso. Dêixis discursivas. Propagandas.

\begin{abstract}
Resumen: Es común encontrar em anuncios de cerveza de Brasil, la repetición de un discurso mediático com explotación de La sensualidad femenina. Dialogando con este tema, esta investigación tiene como objetivo señalar, em algunos anuncios de cerveza, el discurso utilizado no sólo para atraer a los consumidores, sino también para estereotipar a lãs mujeres, destacando sus características físicas e igualando a um producto de consumo. Este estudio bases teóricas de autores como discusión Koch (2004), Marcuschi (2007), com el fin de entender cómo La publicidad discursos anuncios de cerveza se inscriben em la red discursiva. Se buscó investigar cómo se articulan los elementos referenciales del lenguaje para construir el estereotipo de las mujeres como objeto consumo.
\end{abstract}

Palabras-clave: Análisis del Discurso. Deixis discursiva. Publicidad.

\section{Introdução}

A sociedade moderna caracteriza-se, em parte, por uma cultura visual e virtual, construída pela mídia e seus meios de comunicação. Notamos que é comum encontrar materialidades discursivas com efeitos apelativos e o uso sensual da imagem feminina em propagandas de cervejas, veiculadas pela mídia brasileira.

A publicidade é um veículo de grande importância para a sociedade, ocupando espaço em todos os meios, propagando valores e ideologias. Os textos 
publicitários tratam da sociedade para a sociedade, oferecem não apenas produtos e serviços, mas apresentam sonhos e a esperança de uma vida melhor, que visa apenas a um objetivo, a saber, seduzir o consumidor e alcançar seu maior propósito: a venda de produtos.

Dentre várias temáticas apresentadas pela mídia, o erotismo e a sedução corporal se destacam, principalmente, em anúncios de cerveja. Atendendo a essa questão é que este trabalho apresenta como é construído o discurso publicitário, em propagandas de cerveja, que estereotipam a imagem feminina, reafirmando sua condição na sociedade.

Para corpus deste trabalho, foram selecionados quatro anúncios de cerveja da marca Skol. A seleção desses cartazes foi realizada no site da agência publicitária responsável pelas propagandas dessa marca. As quatro imagens são uma sequência de uma única campanha, contendo a mesma estrutura linguística, mudando apenas os referentes.

Este trabalho foi dividido em três partes. A primeira discorre sobre o gênero publicitário, destacando o poder da persuasão na publicidade e o papel feminino nessas propagandas, apresentando outro olhar sobre a figura da mulher nos anúncios de cerveja. Na segunda parte, é introduzido o processo linguístico e semiótico de referenciação, apresentando as abordagens do que seja o signo. Na terceira parte, é discutida a composição da imagem na publicidade, de acordo com as três categorias da semiótica plástica: a cromática, a eidética e a topológica. Serão apresentados os elementos linguísticos usados nos anúncios, com ênfase no processo de referenciação como atividade discursiva, que consiste em construir e reconstruir objetos do discurso, representados a partir de conhecimentos socialmente partilhados e discursivamente (re)construídos.

\section{O gênero anúncio publicitário}

Diariamente lidamos com vários tipos de comunicação. Isso ocorre porque estamos inseridos em uma sociedade e precisamos compartilhar nossas ideias e opiniões. Esses tipos de comunicações recebem denominações diferentes, possuindo objetivos e finalidade específica utilizada de acordo com certas necessidades e ambiente.

Denominamos esses tipos de comunicação gêneros discursivos, uma forma de interação entre indivíduos utilizada para expressar suas opiniões, desejos e pensamentos. Para este trabalho, escolhemos o gênero anúncio publicitário, que possui características, estilos e objetivos específicos e pode ser usado, tanto para finalidade comercial, divulgando uma determinada marca, quanto para promover uma ideia ou acontecimento.

O anúncio publicitário comercial tem como função argumentar e persuadir o público, em propagandas que aparecem em veículos de comunicação como rádio, televisão, outdoors, jornais, revistas e outros. Os anúncios vendem bem mais que 
produtos, vendem ideias, ideologias e, para que seus objetivos sejam alcançados, são utilizados recursos específicos: argumentativos, persuasivos, verbais, não verbais e até intertextualidade e figuras de linguagem, como a metáfora.

As propagandas usam diferentes meios para chamar a atenção do seu público, tais como a imagem, os textos e os sons para atingir e convencer o leitorconsumidor sobre a qualidade de um produto e convencê-lo a adquiri-lo, assim, "a mensagem publicitária cria e exibe um mundo perfeito e ideal, tudo são luzes, calor e encontro numa beleza perfeita não perecível" (CARVALHO, 2004, p. 89).A publicidade utiliza de todos os recursos para alcançar seu objetivo, que é a venda de um produto, e a mensagem, utilizada por essas agências, são, muitas vezes, mascaradas por um mundo maravilhoso para aludir o leitor-consumidor de que o produto ou ideia ali exposta é sempre a melhor opção e, muitas vezes, são fundamentais para a aceitação desses indivíduos na sociedade.

As propagandas criam no consumidor uma necessidade de adquirir o produto anunciado, por mais banal ou supérfluo que seja este produto, criando assim uma necessidade quase primária. Para tanto, escolhem-se determinados ícones para representar o produto e se aproximar do consumidor, demonstrandose, assim, a importância de se escolher corretamente cada elemento usado nelas. $\mathrm{O}$ objetivo é atrair mais consumidores e usar uma linguagem com a qual todos se sintam familiarizados, pois ser atraído pelo anúncio é fundamental. Assim, consequentemente, consegue-se atrair mais pessoas para o consumo desenfreado. Segundo Domingos (2003):

A pergunta do consumidor não era mais "porque preciso de uma geladeira?", mas sim "qual geladeira devo comprar?" Descobriu-se que o produto que tinha imagem mais simpática junto ao consumidor levava vantagem no ponto-de venda. Foi por isso que surgiu a propaganda criativa: para ganhar a preferência do consumidor, diferenciar os produtos e construir a imagem das marcas (DOMINGOS, 2003, p.116).

Para cada público alvo, há um recurso específico. Valores, que necessariamente não existem no produto, são adotados como meio de sedução de clientes, como se a mercadoria fosse algo primordial para a existência das pessoas, distinguindo aquelas que, muitas vezes, não podem obter o produto. De acordo com Ferrés (1998), os comerciais publicitários seduzem, manipulam consumidores e criam tendências, e ainda,

[...] muitos anúncios publicitários funcionam a partir da ausência da racionalidade que as emoções impõem, em uma esfera que não se movimenta pelos parâmetros da lógica racional, mas pela lógica da sedução. Não se vende produtos, mas promessas (FERRÉS, 1998, p.231).

As produções das agências publicitárias, nem sempre, são definidas por critérios que possam interferir na vida social e psicológica de quem as está vendo. 
A preocupação primordial parece ser apenas em propagar o produto e vendê-lo, afirma Fairclough (2001 p.90-91) que "[...] o discurso é uma prática não apenas de representação do mundo, mas de significação do mundo". Os discursos usados nas propagandas são uma representação do mundo em que vivemos, e as agências publicitárias se baseiam na sociedade e em seus acontecimentos para alcançar seu público, ao mesmo tempo em que também o alça a outros discursos.

Nossa pesquisa demonstrou que o postulado que mais influencia a produção das propagandas é o da predominância do público masculino como alvo dos anúncios das cervejarias e consumidores de cerveja. Em nossa compreensão, isso pode reforçar a ideia de superioridade do homem em relação à mulher na sociedade, e essa figura feminina, em nossas análises, aparece como produto eé tomada como parte do universo de consumo masculino.

\section{O papel da mulher nos anúncios publicitários de cerveja}

O Brasil, normalmente, é visto por suas maravilhas, suas belezas naturais, nas quais estão incluídas as mulheres, que em contexto sócio-histórico sempre foram vistas como objeto de desejo. A imagem feminina se tornou pública por valorizar suas características físicas e, nesse sentido, ao retratar isso, a mídia não necessariamente cria novas tendências ou hábitos e, sim os reproduz.

As marcas de cerveja exploram, em tom apelativo, a sensualidade feminina e as empresas publicitárias têm como objeto a mulher, sem se preocupar com quem verá a propaganda e que tipo de cidadão está sendo formado e influenciado por suas produções, referindo-se não apenas a um produto, mas a mulheres que são alvos de preconceitos.

A cerveja não é um produto erótico, mas suas propagandas constroem esse erotismo ao explorar o corpo feminino, acompanhado de um discurso cheio de metáforas, que é claramente voltado para o público masculino, como se eles fossem os únicos consumidores do produto. Observa-se que essas propagandas costumam relacionar seu produto com elementos como mulher, futebol, verão e férias. Em nossa compreensão, isso se dá porque esses elementos são relacionados, de forma recorrente, ao universo masculino. Lins (2006, p. 27) ressalta que os elementos de prazer "dialoga[m] com traços de uma sociedade hedonista, que valoriza o prazer acima de tudo e que lida com o trabalho como uma parte desagradável (um custo que merece recompensa)". Vivemos em uma sociedade em que trabalhar é uma atividade desgastante, chata e que merece um bom descanso, regado a cerveja, mulher e futebol.

Nesse cenário, as marcas de cerveja reforçam a ideia de que a mulher se coloca no espaço masculino para servi-lo. No geral, os homens em seus grupos de amigos são os protagonistas das propagandas, e a mulher, no geral, magra, com corpo bem definido, belas curvas, seios grandes, olhar fascinante, aparece para seduzir e servir aos desejos do homem. 
Os veículos midiáticos usam a imagem sensual da mulher e o desnudo para aguçar os sentidos e chamar atenção do público alvo, visto que o discurso verbal não alcançaria a mesma proporção que o uso imagético da mulher seminua, causando no consumidor prazeres que o produto pode oferecer. Mais que produtos, os anúncios de cerveja expõem a imagem de mulheres que fogem à realidade e que não fazem parte dessas propagandas, justamente por serem mulheres comuns. $\mathrm{O}$ que é sugerido é que, ao se consumir determinada marca de cerveja, os desejos masculinos serão atendidos, inclusive o de ter ao seu lado uma bela mulher.

Entendemos que, por mais espaço que as mulheres já conseguiram alcançar, elas sempre serão vítimas de preconceitos, de opiniões machistas, com estigmas muito semelhantes aos do século passado. A imagem da mulher se tornou comum no ramo da publicidade, seja ela associada à cerveja ou não, configurando, assim, mais que incômodos e, sim, violência física e emocional.

\section{Processos linguístico-semióticos de referenciação}

A semiologia ou Semiótica é a ciência responsável pelo o estudo dos signos, sejam eles linguísticos (semântica / escrita) ou semióticos (signos humanos / da natureza). Ferdinand Saussure (1857-1913) foi um dos primeiros estudiosos do signo linguístico. Para ele, o signo é formado de significado (conceito de uma palavra) e significante (imagem acústica).

Para Saussure (2006), o signo linguístico não tem como função apenas unir uma palavra e uma coisa, mas um conceito e uma imagem acústica, "o signo linguístico é, pois, uma entidade psíquica de duas faces" (SAUSSURE, 2006, p.80), ou seja, a imagem acústica é a aspecto psíquico dos fonemas que arranjam o signo linguístico, enquanto o conceito está relacionado à edificação do sentido no pensamento.

O signo linguístico possui dois princípios primordiais: a arbitrariedade do signo e o caráter linear do significante. Na arbitrariedade do signo há "associação de um significante com um significado" (SAUSSURE, 2006, p.81), isto é, qual seja a palavra ela não está essencialmente ligada a sua sequência de sons que lhe serve como significante, e pode ser representada por outras sequências de acordo com as diversas línguas existentes. A partir dessa arbitrariedade, surgiu o uso do símbolo para indicar o signo linguístico, ou melhor, o significante.

O símbolo não tem como característica a arbitrariedade total, ele é vazio de um vínculo natural entre o significante e o significado. Os símbolos já existentes jamais poderão ser substituídos por um objeto qualquer, temos como exemplo o símbolo da justiça que é representado por uma balança, cuja característica é de cunho social e não pode, individual e arbitrariamente, ser trocada.

O segundo princípio é simples, porém, sua importância é tão valiosa quanto à do primeiro princípio, todo o mecanismo da língua se dá em torno do caráter linear do significante, em oposição aos significantes acústicos, esse princípio é 
concebido pela escrita, pelos gráficos e seus elementos, em que as escolhas dos elementos têm que ocorrer de maneira linear e coerente.

Embora conceito e imagem possam indicar oposição, analisar um texto é procurar encontrar todos os seus arranjos, seu propósito comunicativo, sua temática, seu contexto cultural e sócio-histórico, e para quem foi escrito.

A análise vai muito além do que o autor quer nos passar ou do que quer dizer em seu texto. Para uma análise mais concisa, é preciso ir além do discurso verbal, precisamos considerar as cores e as imagens presentes no texto, visto que todas essas escolhas fazem parte de um conjunto de características que constroem um anúncio publicitário.

A referenciação faz parte do processo de organização textual, tornando a escrita mais coesa e evitando aquelas repetições ou termos desnecessários que tornam a leitura maçante e incompreensível. Sobre isso, Koch (2004) afirma que:

O sujeito, por ocasião da interação verbal, opera sobre o material linguístico que tem à sua disposição, operando escolhas significativas para representar estados de coisas, com vistas à concretização de sua proposta de sentido $(\mathrm{KOCH}, 2004$, p. 61).

O processo de referenciação se estende a todas as atividades linguísticas do sujeito, na qual ele faz as escolhas para representar e concretizar seu diálogo de maneia coesa.

Segundo Marcuschi (2007, p.70) “A língua é um sistema de indeterminações sintático-semânticas que se resolvem nas atividades dos interlocutores em situações sociocomunicativas". O desígnio de como decorre o diálogo é feito pelo sujeito e suas escolhas sintático-semântica, de acordo com sua situação comunicacional.

Koch (2004), ao abordar como o referente é introduzido no modelo textual, aponta os estudos de Prince (1981), em que se afirma que o referente pode surgir de duas formas: não ancorada ou ancorada. A primeira se dá quando um novo objeto é introduzido no discurso, fazendo com que o leitor crie novas memórias. A segunda, ancorada, ocorre quando um novo sujeito é introduzido com elementos de associação presentes no contexto ou contexto. Cavalcante (2005) diz que: é da inter-relação entre língua e práticas sociais que emergem os referentes,
ou "objetos de-discurso", por meio dos quais percebemos a realidade que,
por sua vez, nos afeta. Os referentes passam a ser, assim, não uma entidade
congelada que herdamos e transferimos, mas uma instância de
referencialidade constitutivamente indeterminada e efêmera.
(CAVALCANTE, 2005, p. 125)

É por meio da interação dos sujeitos que os recursos linguísticos disponíveis são utilizados, oferecendo dinâmica e sentido. O processo de referenciação tem como função tecer sentido ao texto, dentro das atividades comunicacionais do indivíduo, sempre situando o tempo e espaço no qual se encontra o sujeito, 
construindo uma afinidade entre a língua e as práticas sociais dos interlocutores e estabelecendo sentido no processo comunicacional.

As anáforas dizem respeito ao resgate dos termos que foram previamente explicitados em um texto. A palavra anapherein foi traduzida do grego, e Ciulla (2002) diz que tem como tradução "repetir", "lembrar" ou "trazer de volta". Analisamos neste processo as anáforas indiretas e diretas e a dêixis.

As anáforas indiretas são construídas por inferências presentes no cotexto. Segundo Marcuschi (2000), esse tipo de anáfora pode ocorrer por meio de expressões nominais e/ ou pronominais "sem que lhes corresponda um antecedente (ou subsequente) explícito no texto. Trata-se de uma estratégia endofórica de ativação de referentes novos e não de uma reativação de referentes já conhecidos, $o$ que constitui um processo de referenciação implícita". Chama a atenção para algo que já está dentro do texto, com novas estratégias linguísticas, como exemplifica Schwarz (2000):

(1) O belo vaso da tia Erna é frágil. A porcelana é muito fina.

(2) Eu quero ir novamente à praia. Adoro o barulho das ondas.

Vale ressaltar que as associações só ocorrem se houver conhecimento de mundo e estereótipos partilhados entre os interlocutores, facilitando uma compreensão do diálogo. No exemplo 1, podemos ver uma relação metonímica entre vaso e porcelana, uma associação, semelhança ou aproximação entre os itens lexicais, que introduz novos elementos sem a necessidade de repetir e tornar a leitura maçante. No exemplo 2, há uma associação entre ondas e praia, criando novos léxicos, por isso, a importância do conhecimento do mundo e cultural entre os interlocutores, para que haja troca de informação.

Diferente das anáforas diretas que são caracterizadas por trazer ao texto um novo referente, relacionado ao outro que foi dito anteriormente, as anáforas indiretas reconstroem a mesma entidade, previamente referida. As retomadas anafóricas são táticas de progressão discursiva, usada não apenas para retomar um referente, mas também com a função de dar sentido ao texto, construindo e reconstruindo os objetos de discurso, segundo Fontana (2014, p.143), "a anáfora é o termo usado para denominar uma expressão linguística cuja interpretação é tomada de alguma outra expressão presente no enunciado ou no contexto". As anáforas são responsáveis pela ininterrupção referencial, estabelecendo uma organização de sentidos. Para este trabalho, também analisamos a dêixis e suas funções, como elementos linguísticos encontrado nos anúncios analisados.

As dêixis ou referência dêictica são expressões ou palavras que apontam para um contexto situacional, de modo que o discurso adquire um novo significado. $\mathrm{Na}$ visão de Witzel (2002), ao considerar o elemento dêitico, postula-se que a instalação de pessoas, espaços e tempos (signos referencialmente vazios) se dá na enunciação e, por isso, não é mais possível analisar o enunciado sem se remeter ao sujeito da enunciação. 
Ao estudar a dêixis discursiva, Maingueneau (1997, p. 42) examina que, se ela existe, "é porque uma formação discursiva não enuncia a partir de um sujeito, de uma conjuntura histórica e de um espaço objetivamente determináveis do exterior, mas por atribuir a cena que sua enunciação ao mesmo tempo produz e pressupõe se legitimar". A ação discursiva não se legitima a partir do sujeito, é preciso atribuir cena ao enunciado.

O sujeito da enunciação/locutor é o ponto central a partir do contexto: "eu" é aquele que diz no momento da fala; "tu" é a pessoa a quem eu se dirijo a fala; "agora" é o momento em que o eu fala; "aqui" é o lugar em que o eu se encontra; "isto" é um objeto que se encontra perto do eu. Podemos classificá-las em dêixis em espacial, social e temporal e pessoal.

Dêixis espacial - assinala os elementos espaciais, tendo como ponto de referência o ambiente em que transcorre a enunciação. Evidencia a relação de proximidade ao lugar ocupador onde se encontra o locutor. A esta função cabem os advérbios ou locuções adverbiais de lugar, os determinantes e pronomes demonstrativos, bem como alguns verbos que indicam movimento.

Dêixis social - é a relação hierárquica entre os participantes da interação discursiva e os papéis por eles adquiridos. Esta função tem como apoio os elementos linguísticos de toda a forma de tratamento.

Dêixis temporal - localiza o tempo, tomando como ponto de referência o "agora" da enunciação. Competem a esta função os advérbios, locuções adverbiais ou expressões de tempo.

Dêixis pessoal - indica as pessoas que participam no discurso, juntam a este grupo os pronomes pessoais, determinantes e pronomes possessivos, sufixos flexionais de pessoa-número e vocativos.

Podemos notar que o processo referencial é uma atividade discursiva, que são desenvolvidos por sujeitos ativos. Há uma escolha dos interlocutores na realização das escolhas de cada elemento linguístico utilizado. E essas escolhas ocorrem à medida que o discurso se desenvolve. Assim explica Leite e Martins (2013):

\footnotetext{
Isso quer dizer que os processos de referenciação são tidos como escolhas do sujeito em função de um querer dizer. Os referentes são vistos como objetos-de-discurso, que não se confundem com a realidade extralinguística, mas (re) constroem-se no próprio processo de interação. São dinâmicos, pois, uma vez introduzidos na memória discursiva, vão sendo constantemente modificados, desativados, reativados, (re) construindo-se o sentido do texto, no curso de uma progressão referencial. (LEITE e MARTINS, 2013, p.45).
}

A partir do momento em que se inicia um discurso, os interlocutores, de maneira dinâmica, selecionam os elementos linguísticos de acordo com aquilo que quer dizer. Para que haja uma interação e sentido é preciso que os sujeitos tenham 
não apenas o mesmo conhecimento linguístico, mas uma relação sociocultural, visto que se não houver esse intercâmbio o discurso não terá sentido.

Na sequência apresentaremos a composição da imagem na publicidade, analisando as imagens de acordo com os elementos linguísticos dêiticos e anafóricos. Levaremos em conta a imagem como parte do discurso e analisaremos sua composição de cores, tamanho e formas presentes em cada anúncio.

Nossa hipótese é que a escolha dos elementos linguísticos e imagéticos têm o intuito de seduzir o leitor-consumidor, não apenas para a venda do produto, mas para reafirmar a identidade masculina e a condição subalterna da mulher no universo masculino e na sociedade.

\section{A composição da imagem na publicidade}

A publicidade é a prática social que mais entusiasma, devido a sua velocidade em alcançar e seduzir seu público. Os textos publicitários são erguidos a partir de textos verbais (escritos e falados) e não verbais (imagens, sons, texturas, cores). Em um mundo de globalização, a escrita já não vem só, ela vem carregada de cores, texturas e imagens que também nos passam uma informação, para a compreensão completa do texto que, muitas vezes, vem carregado de persuasão, passando despercebidos pelo leitor-consumidor.

Somos alfabetizados apenas para ler e compreender os textos verbais. Maingueneau (2005), em seu estudo sobre o discurso, defende que a prática discursiva pode também ser considerada como uma prática intersemiótica que integra produções que pertencem a outros domínios semióticos, tais como o pictórico, o musical etc. $\mathrm{O}$ autor destaca, ainda, a importância do texto verbal associado aos elementos não verbais que complementam e auxiliam na compreensão total do texto, por isso, a importância de ensiná-los.

Os textos publicitários têm com a sociedade uma relação de comunicação, e é por isso que o produto cerveja não é voltado apenas a um determinado público, porém as propagandas analisadas neste trabalho são direcionadas ao público masculino, e expõem a figura feminina por meio de apelos sensuais para conquistar e seduzir seus consumidores.

A seguir, analisaremos quatro propagandas da cerveja Skol que usam a imagem estereotipada da mulher nas propagandas e que utiliza elementos linguísticos carregados de metáforas e apelo sexual.

As propagandas são compostas da mesma temática, apresentando como são algumas peças femininas e de como seriam se o criador desses trajes fosse consumidor da cerveja Skol. As imagens possuem as mesmas cores e elementos linguísticos, mudando apenas seus referentes, que são colocados em comparação dentro da mesma imagem.

Nas imagens, encontramos várias semelhanças, que vão desde as cores que são sempre em tons amarelados, as formas que compõem a imagem, características físicas das mulheres, a seus elementos linguísticos, sempre permitindo que o 
consumidor faça uma analogia entre o produto que está à venda e a mulher que está na propaganda. Para a análise das imagens, adotamos três categorias da semiótica plástica: a cromática, a eidética e a topológica.

As categorias cromáticas estão relacionadas às cores, tonalidades e suas infinitas combinações; na eidética, estão as formas, linhas, as diferentes simetrias e volumes; na topológica estão as formas que ocupam o espaço, alto, baixo, direção e formato.

\section{Análise do Corpus}

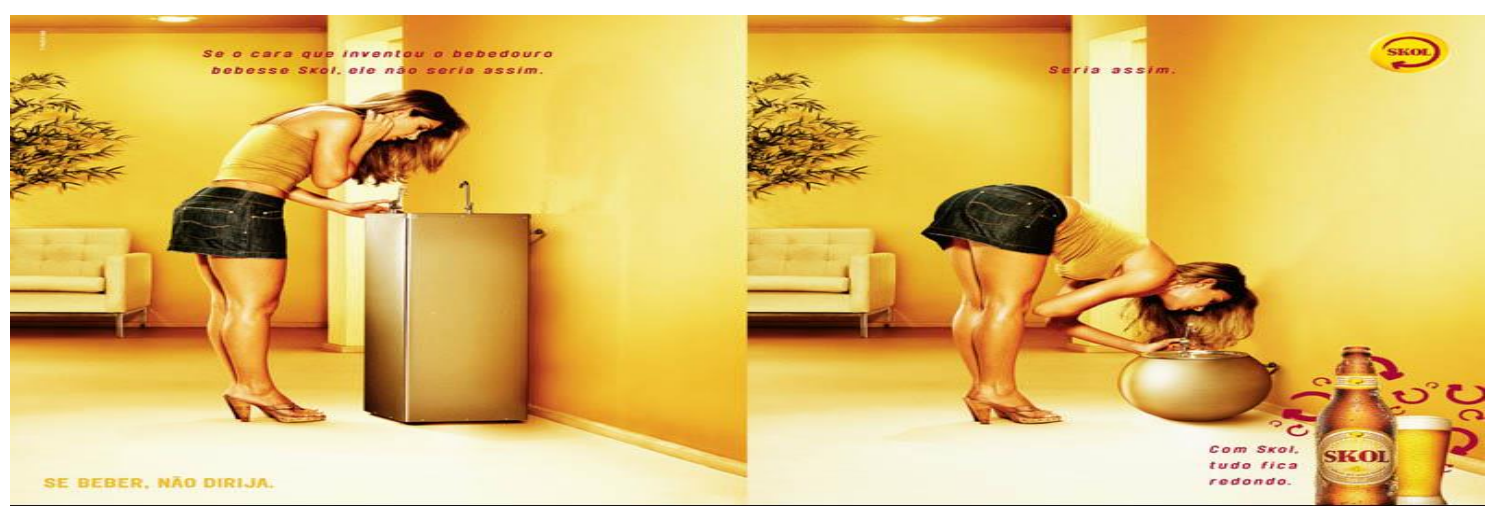

Imagem 1 - Mulher no bebedouro

Na imagem 1, pode-se notar uma mulher loira, com uma minissaia de cor preta tomando água em um bebedouro, as cores presentes são sempre em tons amarelos, nota-se também que o bebedouro muda de formato de acordo com a imagem e os discursos utilizados na imagem.

De acordo com a categoria cromática, há frequência da cor amarelada, no plano de fundo, mudando apenas a tonalidade em algumas áreas que contrasta com a pele bronzeada da mulher. O bebedouro no segundo quadro se refere à logomarca da Skol e, consequentemente, com o líquido amarelo da cerveja. A cor preta presente na saia da mulher chama a atenção para uma parte do corpo feminino, fazendo um apelo sexual. A escolha dessas cores permite ao consumidor relacioná-las com a marca da cerveja Skol, e o preto da saia sugere ao consumidor como tudo fica mais prazeroso quando se consome a cerveja Skol.

Quanto à categoria plástica eidética, que trata das diferentes simetrias, formas e linhas presentes na imagem podem notar as diferentes formas do bebedouro e da posição mulher nos dois lados da imagem. Do lado esquerdo temos um bebedouro quadrado, no qual a mulher está levemente inclinada para tomar água, do lado direito, o bebedouro aparece redondo e em tamanho menor, fazendo com que a mulher se incline mais para tomar água e apareça em uma pose mais sensual.

As formas do bebedouro foram escolhidas justamente para fazer uma referência às marcas de cerveja, o quadrado se refere às outras marcas de cerveja, 
que são tradicionais e "quadradas", já o bebedouro redondo faz uma referência à logomarca da Skol, que é a cerveja "que desce redondo" e proporciona a seus consumidores mais prazer. Podemos notar essa referência, por meio da própria logomarca da cerveja que é "Com Skol tudo fica redondo", ou seja, para o consumidor da cerveja as dificuldades serão encaradas de forma mais prazerosa.

De acordo com a categoria plástica topológica, que traz os formatos dos objetos que ocupam o espaço, alto, baixo e a posição em que se encontram, na imagem esquerda, a mulher está inclinada no bebedouro comum, já na imagem direita a mulher vem mais inclinada no bebedouro redondo e baixo, sugerindo, mais uma vez, os prazeres que a cerveja oferece aos seus consumidores.

Para a análise linguística, consideramos os elementos anafóricos e dêiticos encontrados no texto. Os elementos anafóricos podem ser caracterizados como expressões que retomam termos já existentes no texto, já os dêiticos indicam o tempo ou lugar onde enunciado é produzido, indicando seus participantes. As análises linguísticas não serão feitas isoladamente, mas sempre os relacionando com a imagem, o que contribui claramente para a construção de sentido do texto.

(3) “Se o cara que inventou o bebedouro bebesse Skol, ele não seria assim. Seria assim".

Na sequência 3, o referente principal bebedouro é retomado pelo pronome ele que atua como uma anáfora direta, recuperando o que foi dito, anteriormente, sem alterar seu nome-núcleo. A imagem do bebedouro também é retomada pelo dêitico discursivo assim que na primeira figura remete o bebedouro quadrado, situando o lugar, onde ele se encontra no enunciado e relacionando à imagem do bebedouro com as outras marcas de cerveja, já na segunda representação, o dêitico assim aparece com a mesma função, porém, retoma ao bebedouro redondo e referenciando a marca Skol, fazendo com que a propaganda da cerveja Skol alcance seu objetivo maior que é vender e apresentar a qualidade de seu produto.

$\mathrm{Na}$ imagem 2, os seios cobertos com a tarja, que tem a função de censurar determinadas partes do corpo que não podem ser expostas. A tarja quadrada foi, justamente, escolhida para representar as outras marcas de cerveja, que se mantêm tradicionalmente no decorrer dos anos, já a tarja redonda faz uma referência à marca Skol, que é inovadora e propõe a seus consumidores muito mais prazer. 


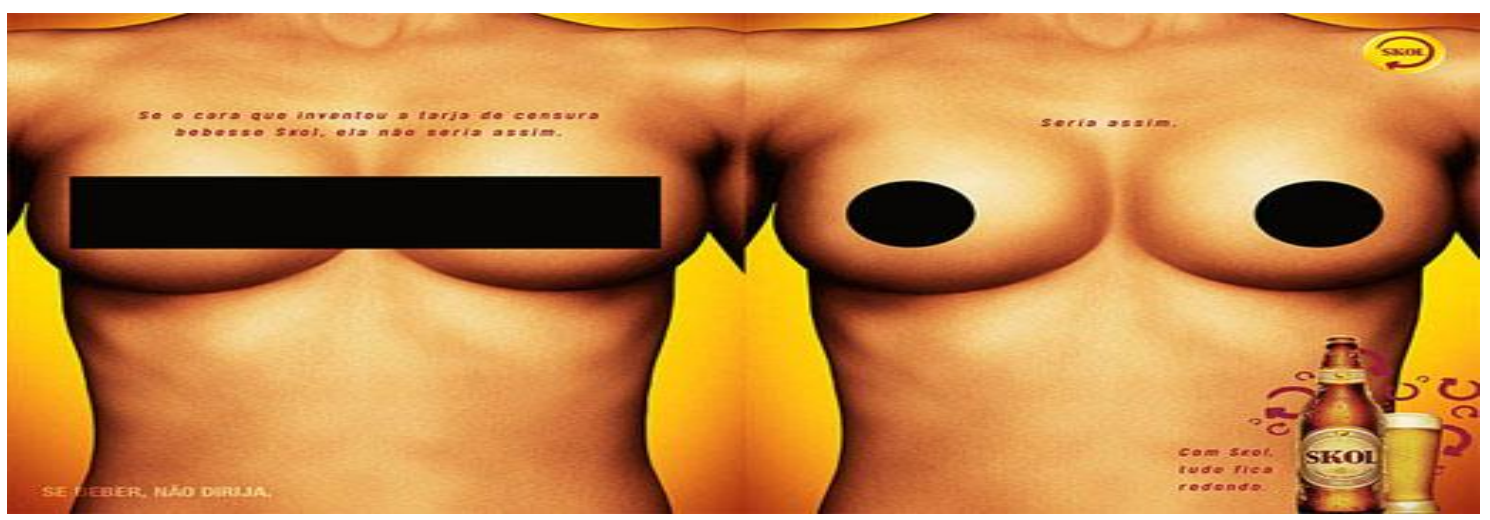

Imagem 2 - Tarja de censura

As cores usadas chamam a atenção por sua vivacidade, o amarelo, o contraste com o tom alaranjado e o bronzeado da pele da mulher está, mais uma vez, presente na propaganda. De acordo com a categoria plástica cromática, essas cores não são escolhidas aleatoriamente, elas foram selecionadas para que o consumidor, ao olhar as cores presentes na imagem, remeta ao líquido da cerveja e até mesmo ao slogan da Skol que também é amarelo. A cor preta também está presente, destacando uma parte sensual do corpo feminino e, consequentemente, estabelecendo uma conotação erótica.

Nota-se que há uma diferença nos formatos das tarjas de censura que, de acordo com a categoria plástica eidética, são uma maneira de relacioná-las com as marcas de cerveja. Na primeira representação, a tarja aparece retangular, protegendo todo o seio da mulher, fazendo uma analogia as outras marcas de cervejas que não se diferenciam, se mantêm iguais; na imagem à direita, a tarja vem arredondada, assim como o símbolo da Skol, que oferece ao consumidor uma visão mais sedutora e prazerosa, porque mostra mais que a tarja quadrada, sugerindo as vantagens e inovações que eles terão ao consumir a cerveja Skol.

A imagem sozinha não teria o mesmo sentido se não viesse acompanhada pelos elementos linguísticos que juntos dão significado ao texto. Para uma análise mais precisa, devemos explorar o campo imagético e linguístico. Portanto segue o texto apresentado:

(4) "Se o cara que inventou a tarja de censura bebesse Skol, ela não seria assim. Seria assim".

Em (4), o referente principal, tarja é retomada pelo pronome ela, que atua como uma anáfora direta, mencionando algo que já foi dito sem alterar seu nome e sentido dentro do texto. A imagem do bebedouro é reforçada pelo elemento dêitico discursivo assim, que aponta a figura do bebedouro, nos levando a comparar o quadrado com as outras marcas de cerveja e o redondo com a marca Skol, fazendo com que a propaganda alcance seu objetivo maior que é o aumento da venda e de consumidores. 


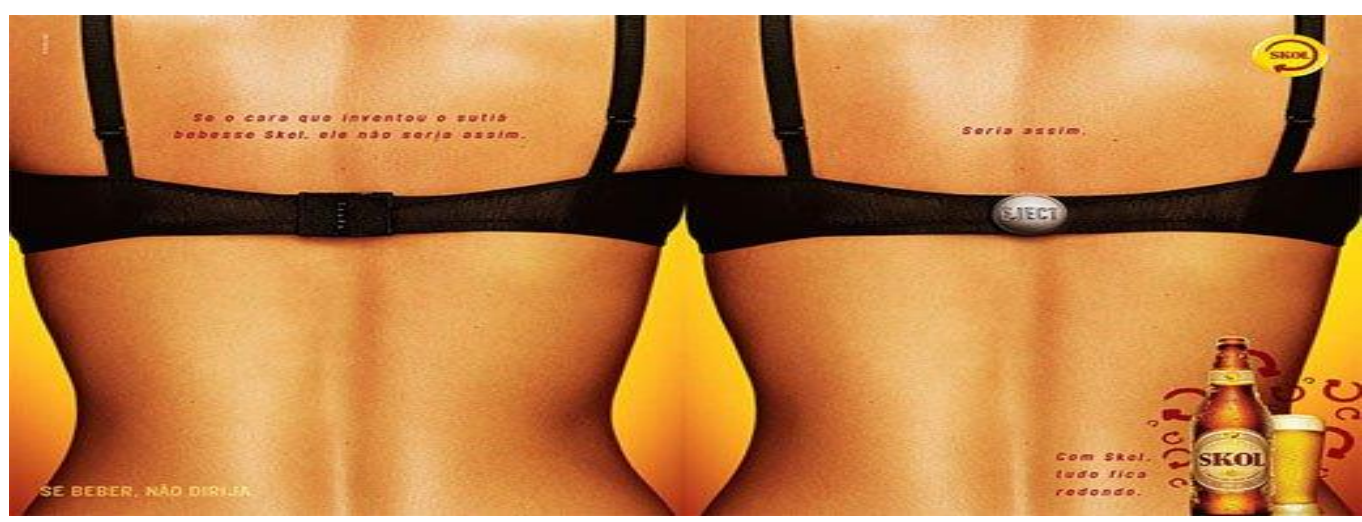

Imagem 3 - Abotoamento do sutiã

A representação feminina portando belas curvas está presente na propaganda e, na imagem 3, há uma comparação de como seria o sutiã se ele fosse inventado por um consumidor da cerveja Skol. A imagem esquerda mostra o sutiã tradicional, com seu fecho retangular e colchetes de grampo, o que, nessa construção sugere a dificuldade em abri-lo. Já na imagem da direta, o fecho aparece redondo e com a palavra "eject", sugerindo mais uma vez, ao consumidor, a facilidade em obter prazer e os bons momentos que a Skol pode proporcionar.

De acordo com a categoria plástica eidética, temos que levar em consideração todas essas características de formas, volumes, as diferentes simetrias encontradas na imagem. Os fechos são diferentes em suas formas, o primeiro é retangular, fazendo mais uma vez menção às outras marcas de cerveja que não inovam, ficam sempre na mesmice, já o fecho da direita é redondo, assim como o slogan da cerveja Skol que apresenta produtos inovadores, proporcionando prazer e facilidade a seus consumidores, mesmo em situações difíceis.

Os elementos linguísticos presentes na imagem também são relevantes e de suma importância para uma compreensão mais objetiva do que apresenta a propaganda. No texto 5, podemos notar a importância da presença dos elementos linguísticos.

(5) “Se o cara que inventou o sutiã bebesse Skol, ele não seria assim. Seria assim".

Na sequência 5, sutiã aparece como referente principal e, para que não seja mencionado todas as vezes que for referido dentro do texto, usa-se o pronome ele, que retoma a palavra sutiã e atua como uma anáfora direta. Temos o elemento dêitico discursivo assim, que localiza e aponta para a imagem do sutiã dentro do discurso e, ao compararmos esses "assim", o texto obtém uma maior dimensão, visto que podemos notar que na primeira representação, o assim aponta para o sutiã com fecho retangular e, no segundo, para o fecho redondo, completando o sentido 
do texto, fazendo com que a propaganda alcance seu objetivo que é vender e atrair mais consumidores.

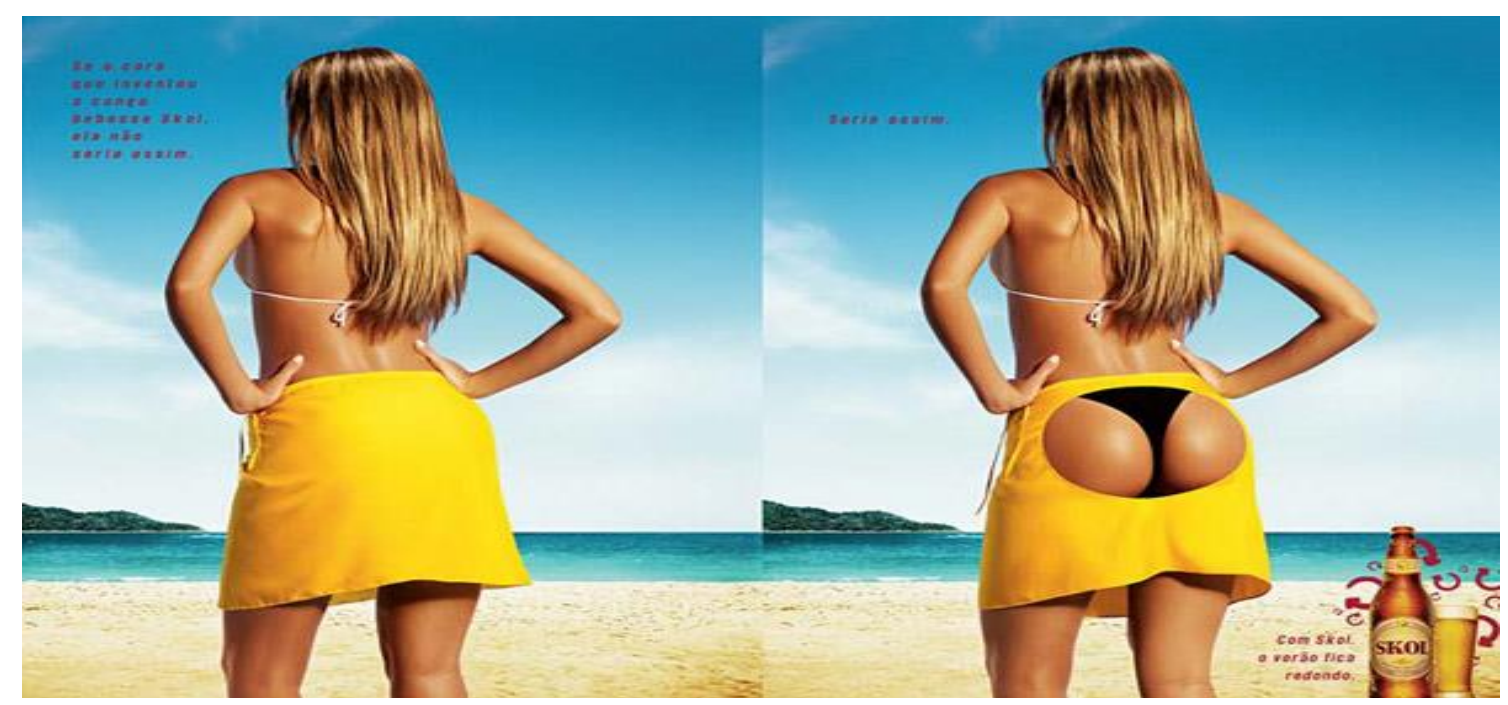

Imagem 4 - Canga de praia

Na imagem 4, a mulher está na praia observando o horizonte, vestida com uma canga tradicional que, na esquerda, protege todas as nádegas. À direita, a canga aparece com um círculo vazado que chama a atenção para as nádegas da mulher.

Quanto às cores, dita pela categoria plástica cromática, notamos uma presença maior do amarelo presente na canga e seu contraste com a areia e com a pele da modelo, essas cores também estão presentes na cerveja. Há, ainda, o preto da calcinha, o que destaca mais uma vez uma parte sensual do corpo feminino. A cor presente na imagem nos faz relacionar a mulher com a cerveja, elas foram escolhidas justamente com o intuito de oferecer ao consumidor essa interpretação, de que, ao consumir a cerveja, ele também pode levar junto a mulher.

Quanto à categoria plástica eidética que estabelece o arranjo das formas e diferentes simetrias, pode-se notar a diferença das cangas. Na esquerda, a representação é tradicional, que simula as outras marcas de cerveja, que permanecem sempre inalteráveis, já a canga da direita difere das outras, pois vem um círculo, referindo-se à cerveja Skol, que possui como slogan um círculo, sempre oferecendo a seus consumidores produtos inovadores e prazerosos.

Para finalizar, podemos notar a postura da mulher, com suas mãos na cintura, sua perna esquerda levemente inclinada para frente, se posicionado de maneira sensual e chamando a atenção para seu corpo e suas curvas, destacando suas nádegas.

Os elementos linguísticos também são responsáveis para a compreensão dos sentidos escondidos por trás da imagem, portanto, apresentamos, em (6), o texto da imagem. 
(6) "Se o cara que inventou a canga bebesse Skol, ela não seria assim. Seria assim."

O pronome ela que é uma anáfora direta, retoma o referente principal canga, sem alterar o sentido do texto ou mencioná-lo novamente. O elemento dêitico assim aponta para a localização do referente que, na primeira figura, remete à canga quadrada e, automaticamente se refere às outras marcas de cerveja, já na segunda, aponta para a canga redonda, referindo-se à marca de cerveja Skol que sempre se diferencia das outras marcas, proporcionando mais prazer e facilidade a seus consumidores.

Pode-se notar que nas imagens anteriores, há a repetição da mesma estrutura sintática, começando com uma situação hipotética "se o cara..." e uma negativa "não seria assim" e, em seguida, uma afirmativa, "seria assim", a estrutura segue em todas as imagens, mudando apenas seu referente. A repetição das cores e da estrutura sintática acontecem com o propósito de fixar a propaganda para seu público, aumentando, assim, seus consumidores, que sempre irão referenciar a cerveja com a cor amarela e tudo circular que verem, pois são essas as características da cerveja Skol.

As propagandas não destacam apenas a cerveja, mas também o corpo da mulher, exposta como um objeto de consumo, igualando-as ao produto e colocando em destaque seu corpo, assemelhando suas curvas com as garrafas de cerveja e aludindo o consumidor das facilidades e momentos de prazerosos que se obtêm ao consumir a cerveja, momentos que vão além de uma rodada de cerveja com os amigos.

\section{Considerações finais}

A finalidade principal deste trabalho consistiu em explicar, com base em conceitos de cenas de enunciação e dêixis discursiva, como se compõem os discursos publicitários, usados em propagandas de cerveja, buscando mostrar o constante uso estereotipado da imagem feminina, que acabam reforçando e construindo uma identidade de superioridade masculina.

Conforme Carvalho (2004), desde o início do século XX o erotismo e o uso sensual da mulher vêm sendo cultivado pela mídia brasileira, em anúncios de cerveja, que estão inseridos nos movimentos culturais, social e histórico. Nos anúncios analisados, constatamos que o estereótipo é a mulher, sempre com sua imagem sensual e sendo objeto de desejo do público masculino, atrelada ao produto cerveja. A mulher, em seus atributos beleza e sensualidade, é usada como estímulo de consumo e venda do produto.

Entendemos que existe um diálogo entre a publicidade e a vida social, em que a publicidade ativa a temática e instaura conhecimentos, impõe modelos e 
imagens que são alcançadas pelo sujeito social que absorve as informações e seus sentidos. Mesmo sabendo que o objetivo final da publicidade é a venda, muitos não têm consciência das estratégias utilizadas, levando em conta todos os estereótipos levantados pela mídia.

O fato de as propagandas de cerveja serem lembradas pelo público se deve aos elementos utilizados para chamar a atenção do consumidor/leitor. A cerveja está relacionada apenas a coisas que proporcionam prazer ao público masculino. Futebol, mulher, praia e cerveja é um quarteto que proporciona prazer e que estão sempre relacionadas à diversão e descanso. Sendo assim, a cerveja é apresentada como passaporte para o sucesso, para a conquista de belas mulheres.

Com esta pesquisa, podemos notar que a trilogia cerveja/ mulher/ futebol revigora os traços de uma sociedade influenciada pela ideologia patriarcal, que aponta a distinção de gêneros, na qual os papéis sociais do homem e da mulher se caracterizam por uma hierarquia. Os homens sempre protagonizam uma história, com um corpo belo, forte e viril; já as mulheres fazem parte de um cenário, sempre subalterna e passiva à situação em que são expostas, como se estivessem ali apenas para servir a seus superiores. Assim, as mulheres são apontadas como objeto de desejo, que estão à disposição daqueles que consomem a cerveja.

A publicidade prioriza esses estereótipos, justamente, por eles estarem agregados à cultura e ao imaginário da nossa sociedade, em que a mulher sempre será vista como objeto, que sua submissão a uma hierarquia ainda se mantém acesa, mesmo com todas as lutas sociais que já marcaram a história.

Conclui-se, questionando as temáticas, que os comercias de cerveja estão propagando em nosso meio estes estereótipos e, por mais que estejam cristalizados e inseridos em nossa cultura, os meios midiáticos corroboram com sua multiplicação, priorizando sempre um estereótipo e não inovando seus valores.

\section{Referências}

CARVALHO, Nelly de. Publicidade: a linguagem da sedução. Universidade Federal de Pernambuco: Ática, 2004.

CIULLA, A. A referenciação anafórica e dêitica-com atenção especial para os estudos dêiticos discursivos. 2002. Dissertação de Mestrado em Linguística - Universidade Federal do Ceará. Fortaleza.

DOMINGOS, Carlos. Criação sem pistolão: segredos para você se tornar um criativo de sucesso. Rio de Janeiro: Elsevier, 2003.

FAIRCLOUGH, N. Discurso e mudança social. Brasília: UnB, 2001.

FERRÉS, Joan. Televisão subliminar: socializando através de comunicações despercebidas. Porto Alegre: Artmed, 1998. 
FONTANA, Maire. A Anáfora Direta: Uma Estratégia de Progressão Discursiva. 2014.

KOCH, Ingedore G. V. Introdução à linguística textual. São Paulo: Martins Fontes, 2004.

LEITE, Maria A. e MARTINS, Renata. Referenciação. Belo Horizonte. 2013.

LINS, Leticia Alves. Cerveja, Mulher, Diversão: representações e diálogos nas propagandas de cerveja. Belo Horizonte, 2006.

MARCUSCHI, Luiz A. Do código para a cognição: o processo referencial como atividade criadora. In: . Cognição, linguagem epráticas interacionais. Rio de Janeiro: Lucerna, 2007.

MAINGUENEAU, D. Gênese dos discursos. Curitiba: Criar Edições, 2005.

MAINGUENEAU, Dominique. Novas tendências em Análise do Discurso. Campinas SP: Pontes: Editora da Universidade Estadual de Campinas, 1997.

SANTANA, Samuel Sena, et. A publicidade seduz os telespectadores e não vende somente produtos, mas também tendências e valores culturais. Cadernos do Sep Adm. $\mathrm{N}^{\mathrm{o}} 3,2006$.

SAUSSURE, Ferdinand. Curso de Linguística Geral. Ed. 27, São Paulo: Cultrix, 2006.

WITZEL, Denise Gabriel. Identidade e Livro Didático: Movimentos Identitários do Professor de Lingua Portuguesa. UEM, 2002

Sites consultados

F/NASCA SAATCHI E SAATCHI disponível emhttp://www.fnazca.com.br/index.php/2001/01/10/skol-pilsen-4/

Acesso 16/04/2016 às 20h10min.

F/NASCA SAATCHI E SAATCHI disponível em http://www.fnazca.com.br/index.php/2005/10/11/skol-pilsen-2/ Acesso 16/04/2016 às 20h08min.

\footnotetext{
i E-mail da autora: cleodetem@gmail.com

ii E-mail da autora: cristina.baraujo@uol.com.br
} 